\title{
The Influence of an Ultrasonic Cleaning Protocol for CAD/CAM Abutment Surfaces on Cell Viability and Inflammatory Response In Vitro
}

\author{
PETER GEHRKE $^{1}$, RALF SMEETS ${ }^{2,3}$, MARTIN GOSAU ${ }^{2}$, REINHARD E. FRIEDRICH $^{2}$, ELIKA MADANI $^{3}$, DIRK $^{2}$ \\ DUDDECK $^{4}$, CARSTEN FISCHER $^{5}$, FLORIAN TEBBEL $^{6}$, ROBERT SADER $^{7}$ and PHILIP HARTJEN ${ }^{2}$ \\ ${ }^{1}$ Private Practice for Oral Surgery, Ludwigshafen, Germany and Department of Postgraduate Education, \\ Master of Oral Implantology, Oral and Dental Medicine, Johann Wolfgang Goethe-University, Frankfurt, Germany; \\ ${ }^{2}$ Department of Oral and Maxillofacial Surgery, \\ University Medical Center Hamburg-Eppendorf, Hamburg, Germany; \\ ${ }^{3}$ Department of Oral and Maxillofacial Surgery, Division of Regenerative Orofacial Medicine, \\ University Hospital Hamburg-Eppendorf, Hamburg, Germany; \\ ${ }^{4}$ Medical Materials Research Institute, Berlin, Germany; \\ ${ }^{5}$ Dental Laboratory, Sirius Ceramics, Frankfurt am Main, Germany; \\ ${ }^{6}$ Mechanical Engineering, Heddesheim, Germany; \\ ${ }^{7}$ Department for Oral, Cranio-Maxillofacial and Facial Plastic Surgery, \\ Medical Center of the Goethe University, Frankfurt, Germany
}

\begin{abstract}
Background/Aim: To evaluate the effect of an ultrasonic cleaning and disinfection method for CAD/CAM abutment surfaces on cell viability and inflammatory response in vitro. Materials and Methods: Untreated and manually polished surfaces of CAD/CAM generated titanium and zirconia disks were randomly assigned, either to a 3-step ultrasonic cleaning and disinfection process (test: TiUF, TiPF, ZrUF, ZrPF) or to 30 sec steam cleaning (control: TiUS, TiPS, ZrUS, ZrPS). Pre-cleaning surface analyses using scanning electron microscopy (SEM), energy dispersive $X$-ray spectroscopy (EDX), and surface profilometry were performed. Human gingival fibroblasts (HGFs) were cultured on test and control specimens and subsequently examined for cell viability and inflammatory response. Expression of acute inflammatory cytokine interleukin (IL)-6 and vascular endothelial growth factor $A$ (VEGFA) were assessed by means of RT-qPCR. Results: Cells on all specimens exhibited a satisfactory viability, indicating firm attachment. Cells on polished zirconia
\end{abstract}

This article is freely accessible online.

Correspondence to: Peter Gehrke, Bismarckstraße 27, 67059 Ludwigshafen, Germany. Tel: +49 62168124456, Fax: +49 62168124469, e-mail: dr-gehrke@ prof-dhom.de

Key Words: CAD/CAM implant abutments, ultrasonic cleaning, steam cleaning, cell viability, inflammatory response. samples, cleaned by means of sonication ( $\mathrm{ZrPF})$, exhibited significantly higher viability than cells on the same material cleaned by steam (ZrPS), $p=0.019$. For all other three material/ surface treatment combinations (TiU, TiP, ZrU), no such difference was observed between the cleaning methods. The messenger ribonucleic acid (mRNA) levels of IL-6 and VEGFA were between 50 and $105 \%$ of that of the control cells on the non-toxic control surface. mRNA levels of IL-6 and VEGFA correlated well with each other. Conclusion: Except for higher viability of cells cultured on polished zirconia specimens, no universally applicable advantage could be found for the ultrasonic cleaning procedure for zirconia and titanium abutment surfaces regarding cell viability, IL-6 expression or VEGFA expression. The cleaning procedures did not have any negative effect either.

Soft tissue adhesion to the transmucosal part of an implant abutment is essential, as it provides a protective seal which prevents bacterial invasion and subsequent inflammation (1, 2 ). Peri-implant mucosa is composed of well-keratinized oral, sulcular, and junctional epithelium, as well as underlying connective tissue (3). Human gingival fibroblasts (HGFs) are precursors of cells in the connective tissue of the mucosal seal and are involved in the homeostasis of collagen fibers around implant abutments (4, 5). Surface characteristics of the abutment determine to a large extent the quality of mucosal attachment (6). Surface topography, wettability and free energy determine cell reactions $(7,8)$, whereas contaminants and chemical debris could adversely 
affect the surface-cell interaction (9-11). CAD/CAM fabrication procedures for customized implant abutments made of titanium and zirconia may contaminate abutment surfaces through lubricants, waxes, generic pollutants, and wear microparticles. $(12,13)$. The presence of contaminants at the abutment platform-level has been suggested to be associated with inflammation and titanium particles were demonstrated to activate osteoclastic action (14). For this reason, cleaning and disinfection of the abutment surface is essential. However, effects of various cleaning procedures have been controversially discussed (15-18) and a conclusive clinical relationship between the abutment cleanliness and the maintenance of peri-implant bone levels has yet to be proven (19).

European health regulations, e.g. BS EN ISO 17664: 2004 (International Organization for Standardization) have approved cleaning and disinfection procedures for semicritical medical devices, such as CAD/CAM customized implant abutments. They consider either an ultrasonic cleaning with approved disinfectants or the sterilization of the components at $134^{\circ} \mathrm{C}$. However, vapor at such a high temperature and pressure may damage the crystal framework of ceramic abutments and therefore increase the risk of breakage (20-24). Although often conducted in daily practice, steam cleaning is not an approved cleaning and disinfection approach. While in vivo and in vitro investigations have reported that a plasma pre-treatment could be beneficially adopted for abutment cleaning $(9,10,25)$, a recent trial of Farronato et al. observed that decontamination with argon plasma alone might not be effective enough (26). It should, however, be noted that plasma processing is not a validated cleaning method for abutment cleaning, following technical procedures of customization.

An ultrasonic treatment is a proven and authorized cleaning method and has been alternatively recommended to clean titanium and ceramic abutments $(13,19)$. Ultra-high frequency waves in combination with a disinfecting agent mechanically and chemically remove contaminants from the surfaces. Nevertheless, the impact of this cleaning method on the attachment and inflammatory response of human gingival fibroblasts (HGFs) has not been yet investigated. The aim of the current study was, therefore, to examine the effect of a 3-step ultrasonic cleaning and disinfection protocol for CAD/CAM abutments on cell viability and inflammatory response in vitro. HGFs were cultured on untreated and manually polished titanium and zirconia CAD/CAM abutment surfaces. Cell viability, as well as messenger ribonucleic acid (mRNA) levels of interleukin (IL)-6 and vascular endothelial growth factor A (VEGFA) were investigated, which are indicative parameters for immune responses (27). The null hypothesis was that an ultrasonic decontamination of CAD/CAM abutment surfaces improves cell viability and reduces the inflammatory response.

\section{Materials and Methods}

Specimens and reference materials. A total of 64 disks, each with a diameter of $10 \mathrm{~mm}$ and a height of $1.7 \mathrm{~mm}$ (BEGO Implant Systems $\mathrm{GmbH} \& \mathrm{Co}$. KG, Bremen, Germany), made of grade 4 titanium and yttria-stabilized tetragonal zirconia (Y-TZP) with CAD/CAM machined surfaces were used in the present study. The CAD/CAM generated titanium $(\mathrm{Ti})(\mathrm{n}=32)$ and zirconia $(\mathrm{Zr})(\mathrm{n}=32)$ disks were divided to one half each $(n=16)$ according to their post-production surface treatment in a polishing step (Figure 1). While one Ti-group and one $\mathrm{Zr}$-group remained unprocessed (named $\mathrm{TiU}$ and $\mathrm{ZrU}$ for "titanium unprocessed" and "zirconia unprocessed"), the surface of the other group was manually polished by the same operator (CF) by a two-step protocol for $5 \mathrm{~min}$ using Panther Edition Lense 260 rough and 260 smooth (Sirius Ceramics, Frankfurt, Germany). Following on from here, this polishing protocol is referred to as "Panther polishing" and the polished groups are named TiP and $\mathrm{ZrP}$ for "titanium Panther polished" and "zirconia Panther polished" (Figure 2).

Prior to cleaning, 16 disks, four titanium and zirconia for each group (TiU, TiP, $\mathrm{ZrU}, \mathrm{ZrP}$ ) were used for surface analysis (scanning electron microscopy and profilometry). The untreated and polished titanium and zirconia disks were divided into two additional subgroups, consisting of an equal number of 4 disks each, to be used in the cell culture experiments and receiving two different treatments in a cleaning step (steam cleaning vs. 3-step ultrasonic cleaning). Four titanium and zirconia disks for each sub-group were randomly allocated as test and control group. The disks of the test groups consisting of $n=4$ specimens each, underwent a standardized 3 -step ultrasonic cleaning procedure reported in a previous study (13) and were named "titanium unprocessed Finevo cleaned" (TiUF), "titanium Panther polished Finevo cleaned" (TiPF), "zirconia unprocessed Finevo cleaned" (ZrUF), "zirconia Panther polished Finevo cleaned" (ZrPF), respectively. These samples were cleansed three times in an ultrasonic bath at $30^{\circ} \mathrm{C}$ for 5 min each. The first bath contained an antibacterial cleansing solution (FINEVO 01, Sirius Ceramics, Frankfurt, Germany), the second bath contained $80 \%$ ethylalcohol, and the third bath contained medically pure water (aqua dest.) (Figure 3).

Titanium and zirconia disks in the control sub-groups, consisting of $n=4$ specimens each, were solely steam-cleaned for $30 \mathrm{sec}$ (VAP 1; Zhermark, Cologne, Germany) and named "titanium unprocessed steam cleaned" (TiUS), "titanium Panther polished steam cleaned" (TiPS), "zirconia unprocessed steam cleaned" (ZrUS), "zirconia Panther polished steam cleaned" (ZrPS), respectively.

Human gingival fibroblasts (HGFs) were cultured on test and control specimens and subsequently examined for cell viability and inflammatory response. As a toxic control surface, RM-A, a polyurethane film sheet containing $0.1 \%$ zinc diethyldithiocarbamate (Hatano Research Institute, Hadano, Kanagawa, Japan), cut to yield disks with a diameter of $10 \mathrm{~mm}$, was employed. As a nontoxic control surface, TC coverslips (cat. no. 83.1840.002; Sarstedt, Nürmbrecht, Germany) were used.

Topography and surface analysis. A total of 16 disks (four in each group TiU, TiP, ZrU, ZrP) were randomly selected for determination of surface topography and roughness prior to the assigned cleaning attempt. The test and control specimens were examined for average surface roughness $(\mathrm{Sa})$, maximum height of the selected surface $(\mathrm{Sz})$, and developed interfacial area ratio $(\mathrm{Sdr})$ by means of 


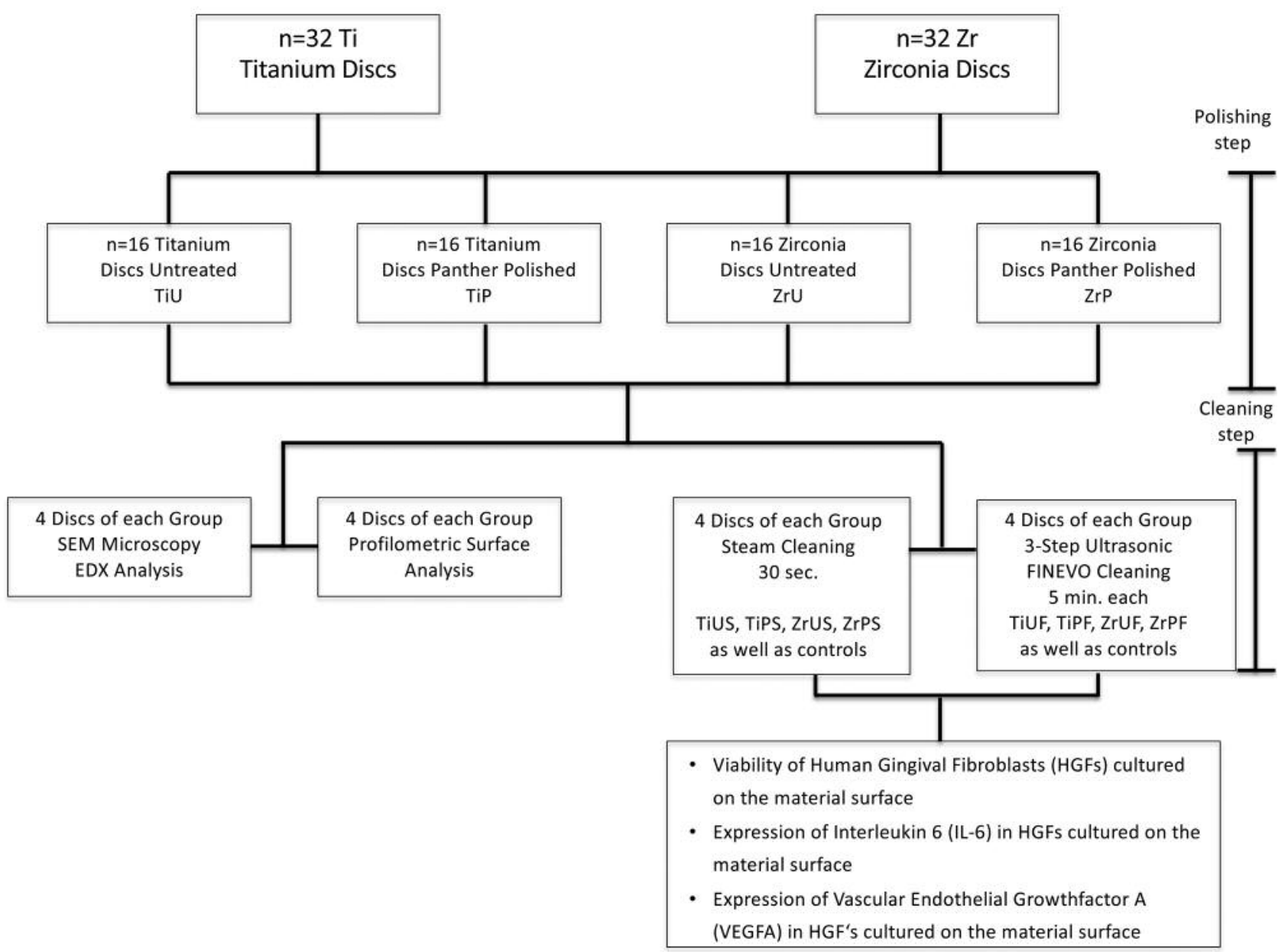

Figure 1. Study design for specimen treatments, cleaning procedures, SEM-, EDX-, profilometric analysis and cell culture experiments.

profilometric focus-variation microscopy (Infinite Focus Standard G4, Alicona Imaging GmbH, Graz, Austria).

Microscopic and chemical analysis. After post-production surface treatment, but prior to the cleaning step, a total of 16 disks (four in each group $\mathrm{TiU}$, TiP, $\mathrm{ZrU}, \mathrm{ZrP}$ ) were randomly allocated to scanning electron microscopy (SEM) (Phenom ProX, PhenomWorld B.V., Eindhoven, Netherlands) and energy dispersive X-ray spectroscopy (EDX) analysis. The emitted $\mathrm{x}$-rays detected by EDX allow to obtain chemical profiles of the elements found on the abutment surfaces.

Cell culture, viability and gene expression assays. The titanium (Ti) and zirconia $(\mathrm{Zr})$ disks of the test (TiUF, TiPF, ZrUF, ZrPF) and control group (TiUS, TiPS, ZrUS, ZrPS) were examined regarding cell viability and inflammatory response of primary human gingival fibroblasts (HGFs) cultured directly on their surfaces. HGFs were obtained from the American Type Culture Collection (ATCC, Manassas, VA, USA). HGFs were cultured in "Fibroblast Basal Medium" (ATCC, Manassas, VA, USA) supplemented with the "Fibroblast Growth Kit-Low serum" (ATCC, Manassas, VA, USA) and penicillin/streptomycin $(100 \mathrm{U} / \mathrm{ml}$ each from Life Technologies,
Carlsbad, CA, USA). The specimens were subsequently placed into a well of a 12 -well cell culture plate onto which $1 \times 10^{5} \mathrm{HGFs}$ were seeded in $1 \mathrm{ml}$ medium. For each material/surface treatment combination (TiUS, TiUF, TiPS, TiPF, ZrUS, ZrUF, ZrPS, ZrPF) as well as for nontoxic and toxic controls, 4 replicates were set up for measuring viability of attached cells and for RNA extraction. The plates were incubated at $37^{\circ} \mathrm{C}$ and $5 \% \mathrm{CO}_{2}$ overnight. On the next day, the specimens with cells on their surfaces were washed once in phosphate buffered saline (PBS, Life Technologies, Carlsbad, CA, USA) and transferred to wells in new plates. Viability of cells attached to the surface of the specimens were measured using a CellTiter $96^{\circledR}$ AQueous One Solution Assay (Promega, Madison, WI, USA) following the manufacturers' instructions. Total RNA was purified from the cells attached to the surface of the specimens using a NucleoSpin ${ }^{\circledR}$ kit (Macherey-Nagel, Düren, Germany). Complementary DNA (cDNA) was synthesized using the GoScript ${ }^{\mathrm{TM}}$ Reverse Transcription System with Oligo(dt)15 primers (Promega, Madison, WI, USA). mRNA of IL-6 and VEGFR was measured in four replicates using dual-probe RT-qPCR. Each assay contained components of two TaqMan (Thermo Fisher Scientific, Waltham, MA, USA) assay kits, one for the target mRNA and the other for mRNA of glyceraldehyde phosphate dehydrogenase (GAPDH), which was used 


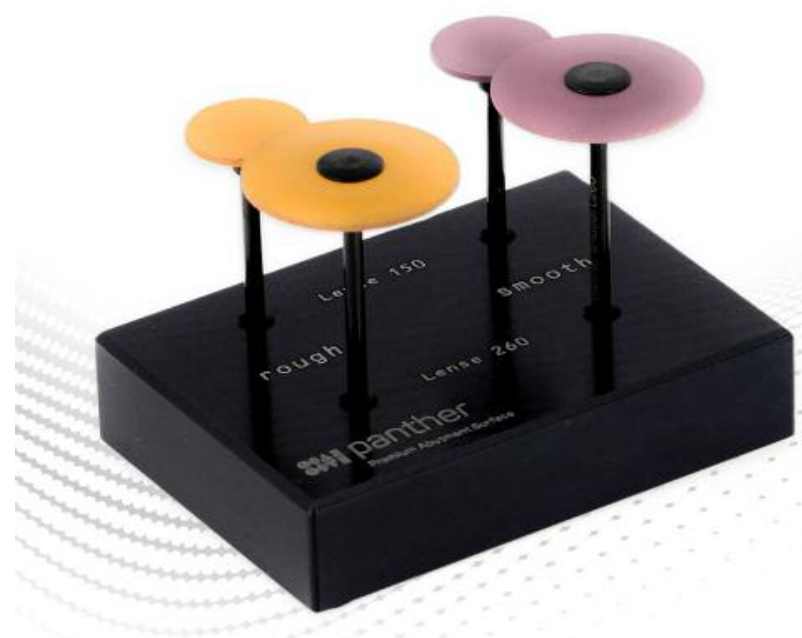

Figure 2. Polishing instruments Panther Edition Lense 260 rough and 260 smooth used for 5 min polishing of the titanium and zirconia CAD/CAM test disks (TiPU, ZrPU).
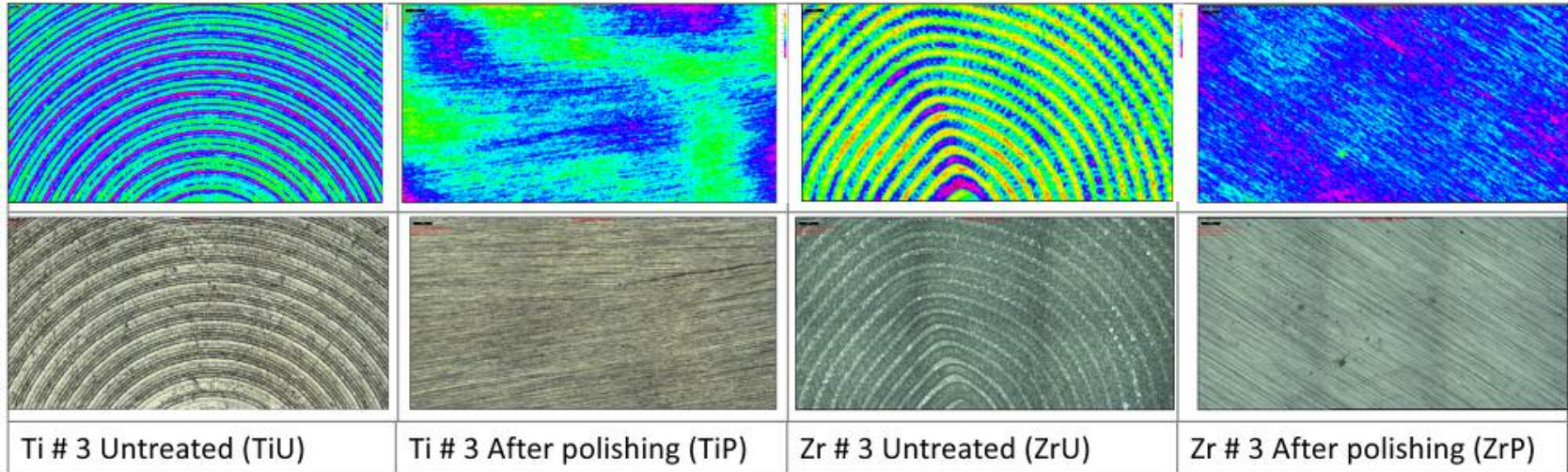

Figure 3. Ultrasonic cleaning protocol. Three times ultrasonic bath at $30^{\circ} \mathrm{C}$ for 5 min each. 1) antibacterial FINEVO cleaning solution; 2) $80 \%$ ethylalcohol; 3) aqua dest.

Ti \# 3 Untreated (TiU)

Ti \# 3 After polishing (TiP)

$\mathrm{Zr} \# 3$ Untreated (ZrU)

Zr \# 3 After polishing (ZrP)

Figure 4. Profilometric example images of height display color scale (top row) and true color representation (bottom row) of untreated and Panther polished titanium and zirconia test specimens.

as an internal reference gene. Cycle numbers at a defined threshold for target (Ct target) and GAPDH (Ct GAPDH) were read and the difference between the two was calculated as $\Delta \mathrm{Ct}=\mathrm{Ct}$ target $-\mathrm{Ct}$ GAPDH. Subsequently, the four $\Delta \mathrm{Ct}$ values in the four replicates for one sample were used to calculate the mean $\Delta \mathrm{Ct}$ for each sample. Relative copy number of target mRNA to fictive 1000 copies of GAPDH-mRNA were calculated as $1000 / 2^{m e a n} \Delta \mathrm{Ct}$. Copy numbers were converted to percent of copy numbers in control cells cultured on culture plate surface.

Statistical analysis. Statistical analysis was performed using the software Graphpad Prism 5 (GraphPad Software, Inc., La Jolla, CA,
USA). The statistical significance of differences between test groups was determined using unpaired, two-tailed Student's $t$-test analysis. The level of significance was set at $5 \%(p<0.05)$.

\section{Results}

Topography and surface analysis. Descriptive characteristic variables for the avarage surface roughness (Sa $\mu \mathrm{m})$, developed interfacial area ratio $(\mathrm{Sdr} \%)$, and maximum height of the selected surface $(\mathrm{Sz})$ according to surface treatment (TiU, $\mathrm{ZrU}$, TiP, $\mathrm{ZrP}$ ) are shown in Table I. While 


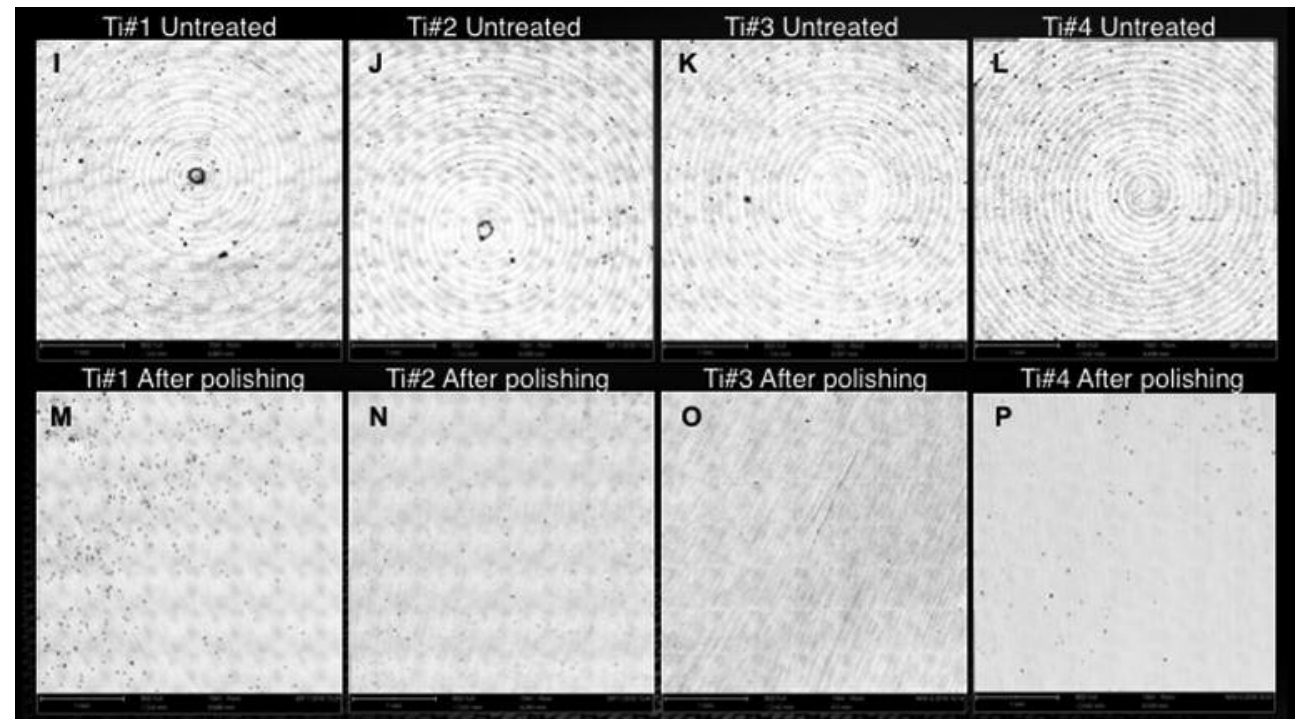

Figure 5. SEM pictures (500x) of untreated titanium disk specimens (I-L) with contamination particles of different size and centric milling grooves from CAD/CAM machining. Debris to a different extent and surface smoothing effect after a 2-step polishing procedure with Panther polisher (MP) $(500 x)$.

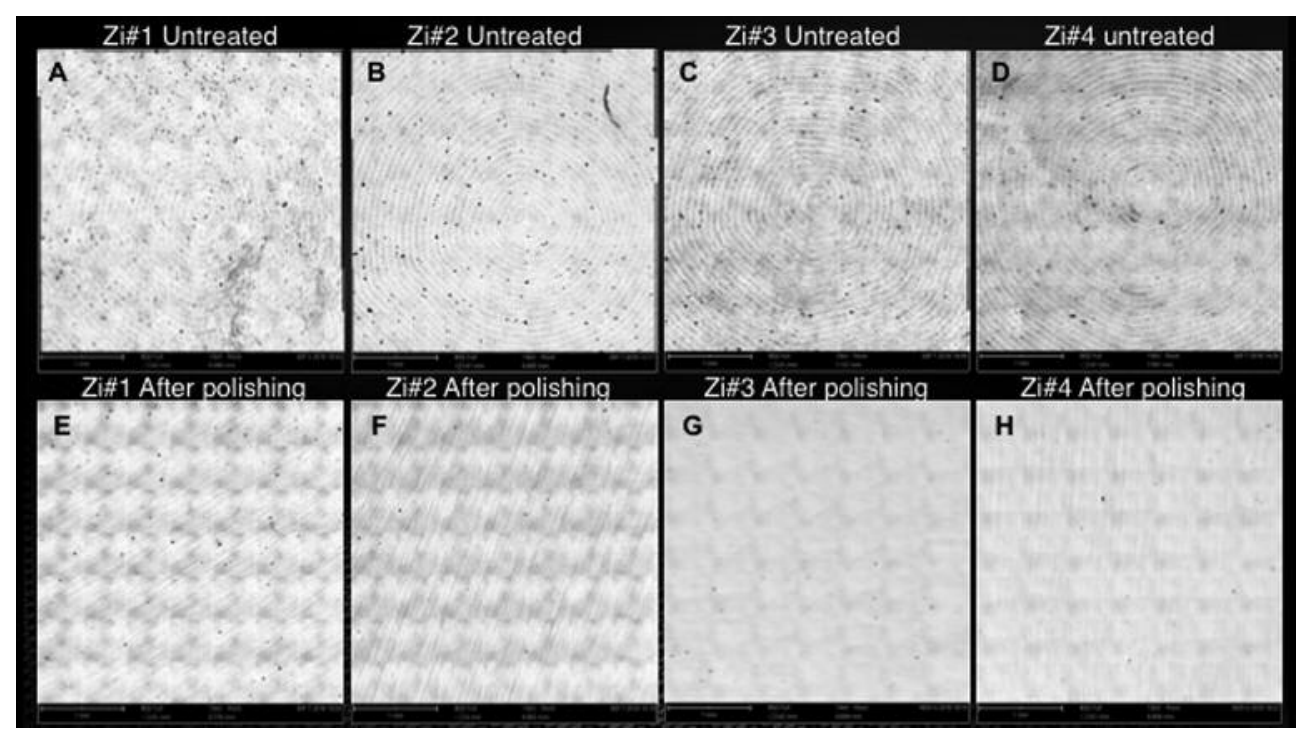

Figure 6. SEM pictures (500x) of untreated zirconia disk specimens (A-D) with visible contamination particles and circular milling grooves from CAD/CAM machining. Reduced surface contamination with scattered residues and surface leveling after 2-step polishing procedure with Panther polisher $(E-H)(500 \times)$.

the Panther polishing protocol reduced the average surface roughness values $(\mathrm{Sa})$ by half for the examined titanium specimens, this phenomenon was not observed for the zirconia specimens. Profilometric images of the untreated and polished titanium and zirconia surfaces displayed differences depending on the conducted treatment (Figure 4).
Microscopic and chemical analysis. SEM analysis revealed production-induced wear particles, debris as well as organic and inorganic contaminants on the CAD/CAM generated surfaces of the untreated and polished titanium and zirconia disks. All examined test specimens displayed surface contamination of various degree and particle size. On- and/or 


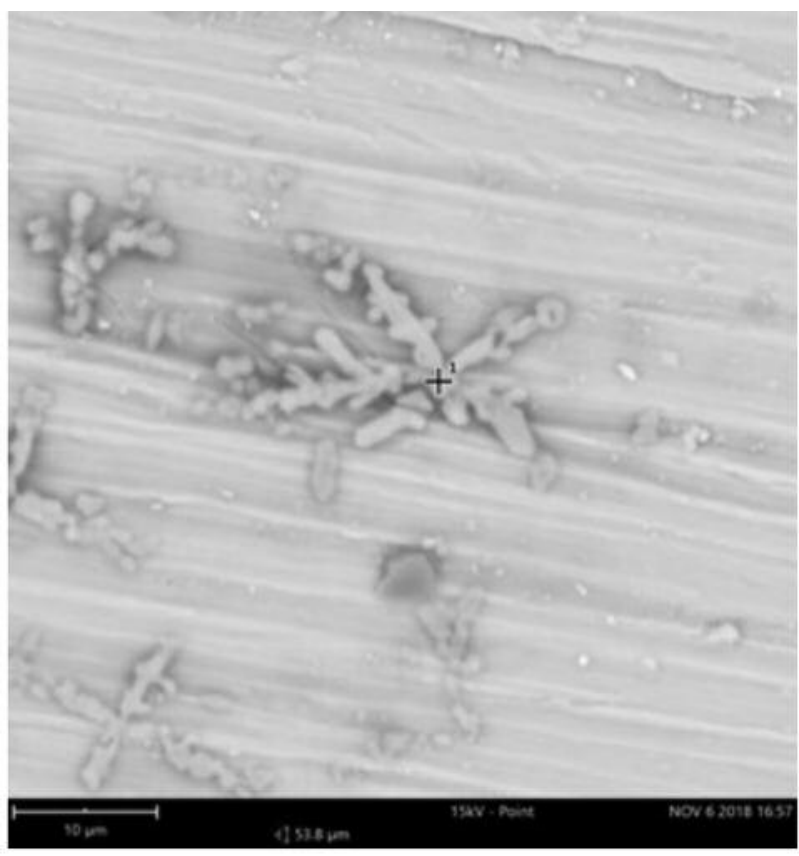

\begin{tabular}{|l|l|l|r|r|}
\hline $\begin{array}{l}\text { Element } \\
\text { Number }\end{array}$ & $\begin{array}{l}\text { Element } \\
\text { Symbol }\end{array}$ & $\begin{array}{l}\text { Element } \\
\text { Name }\end{array}$ & $\begin{array}{l}\text { Atomic } \\
\text { Conc. }\end{array}$ & $\begin{array}{l}\text { Weight } \\
\text { Conc. }\end{array}$ \\
\hline 11 & $\mathrm{Na}$ & Sodium & 31.77 & 24.71 \\
\hline 8 & $\mathrm{O}$ & Oxygen & 21.35 & 11.56 \\
\hline 17 & $\mathrm{Cl}$ & Chlorine & 19.22 & 23.05 \\
\hline 22 & $\mathrm{Ti}$ & Titanium & 18.32 & 29.67 \\
\hline 19 & $\mathrm{~K}$ & Potassium & 6.05 & 8.00 \\
\hline 13 & $\mathrm{Al}$ & Aluminium & 3.29 & 3.00 \\
& & & & \\
\hline
\end{tabular}

Figure 7. Example of EDX spectrum with SEM image (5000x) and elements found on spot 1 of titanium disk Ti\#2 (TiP) after 2-step polishing (Panther). Contamination with sodium ( $\mathrm{Na}$ ) and chlorine $(\mathrm{Cl})$.

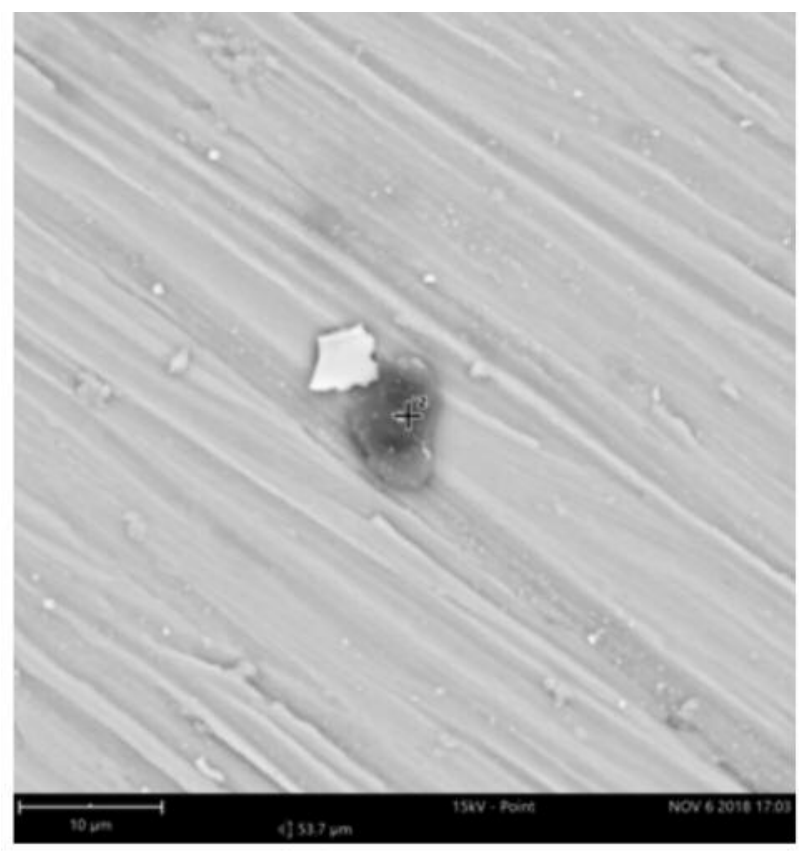

\begin{tabular}{|l|l|l|r|r|}
\hline $\begin{array}{l}\text { Element } \\
\text { Number }\end{array}$ & $\begin{array}{l}\text { Element } \\
\text { Symbol }\end{array}$ & $\begin{array}{l}\text { Element } \\
\text { Name }\end{array}$ & $\begin{array}{l}\text { Atomic } \\
\text { Conc. }\end{array}$ & $\begin{array}{l}\text { Weight } \\
\text { Conc. }\end{array}$ \\
\hline 6 & $\mathrm{C}$ & Carbon & 69.19 & 38.91 \\
\hline 22 & $\mathrm{Ti}$ & Titanium & 22.00 & 49.31 \\
\hline 14 & $\mathrm{Si}$ & Silicon & 3.98 & 5.23 \\
\hline 13 & $\mathrm{Al}$ & Aluminium & 3.77 & 4.77 \\
\hline 16 & $\mathrm{~S}$ & Sulfur & 0.82 & 1.24 \\
\hline 23 & $\mathrm{~V}$ & Vanadium & 0.23 & 0.55 \\
\hline
\end{tabular}

Figure 8. Example of EDX spectrum with SEM image (5000x) and elements found on spot 2 of titanium disk Ti\#5 (TiP) after 2-step polishing (Panther). Contamination with carbon $(C)$ and other elements.

Aluminum is also an ingredient of polishing pastes and could have, consequently, originated from polishing procedures. While traces of sulfur seem to be residues from cleaning attempts during the main production and cleansing procedure of $\mathrm{CAD} / \mathrm{CAM}$ products, traces of chlorine indicate an insufficiently removed cleansing solution during central production.

Cell viability. Cell viability on the surfaces of all material/ surface treatment combinations (TiUS, TiUF, TiPS, TiPF, ZrUS, ZrUF, ZrPS, ZrPF) was roughly comparable to that of the cells on the non-toxic control surface, indicating a firm attachment (Figure 10). Cells on Panther polished and ultrasonically cleaned zirconia disks (ZrPF) exhibited 


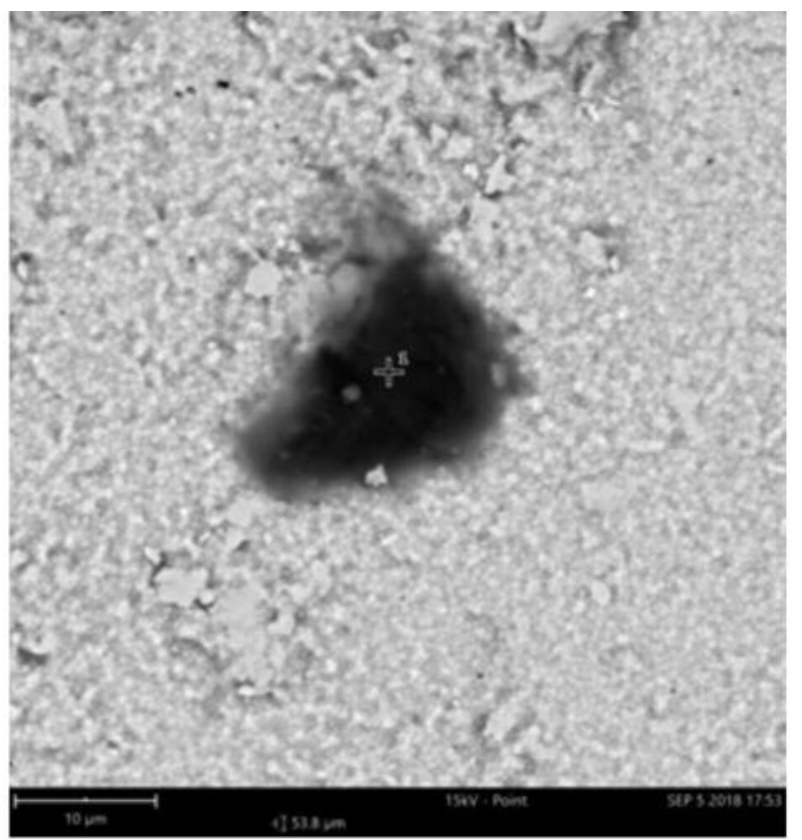

\begin{tabular}{|l|l|l|r|r|}
\hline $\begin{array}{l}\text { Element } \\
\text { Number }\end{array}$ & $\begin{array}{l}\text { Element } \\
\text { Symbol }\end{array}$ & $\begin{array}{l}\text { Element } \\
\text { Name }\end{array}$ & $\begin{array}{l}\text { Atomic } \\
\text { Conc. }\end{array}$ & $\begin{array}{l}\text { Weight } \\
\text { Conc. }\end{array}$ \\
\hline 40 & $\mathrm{Zr}$ & Zirconium & 17.80 & 56.98 \\
\hline 6 & $\mathrm{C}$ & Carbon & 59.11 & 24.91 \\
\hline 8 & $\mathrm{O}$ & Oxygen & 21.08 & 11.83 \\
\hline 39 & $\mathrm{Y}$ & Yttrium & 2.01 & 6.27 \\
\hline
\end{tabular}

Figure 9. Example of EDX spectrum with SEM picture $(5000 \times)$ and elements found on spot 1 of untreated zirconia sample disk $\mathrm{Zi \# 1} \mathrm{(ZrU).}$ Contamination with carbon $(C)$.

significantly higher viability compared to cells on the same material but solely cleaned by steam (ZrPS), $p=0.019$. For the other tested material/surface treatment combinations (TiU, TiP, ZrU), no such difference was observed between the cleaning methods. Moreover, no significant differences were observed between untreated/steam cleaned (TiU) and Panther polished/ Finevo cleaned (TiPF) titanium samples as well as between untreated/ steam cleaned (ZrU, ZrUS) and Panther polished/ Finevo (ZrPF) cleaned zirconia samples.

Gene expression. The mRNA levels of IL-6 expressed in HGFs cultured on test and control samples of all material/ surface treatment combinations (TiUS, TiUF, TiPS, TiPF, ZrUS, ZrUF, ZrPS, ZrPF) ranged between 68 and $105 \%$ of that of the cells cultured on the nontoxic control surface (Figure 11A). The mRNA levels of VEGFA ranged between 50 to $98 \%$ of control cells cultured on the culture plate surface (Figure 11B). Notably, mRNA expression levels for

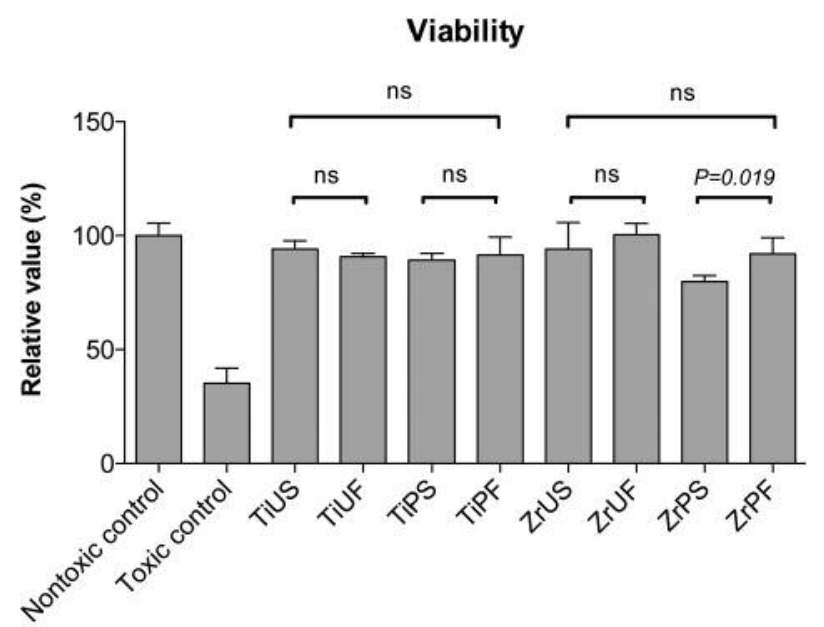

Figure 10. Viability of human gingival fibroblasts grown on surfaces of zirconia and titanium cleaned by steam or by a 3-step ultrasonic cleaning and disinfection protocol. Mean and standard deviation of 4 replicates are given in columns and bars. Statistical significance of differences between the indicated test groups was determined using unpaired, two-tailed Student's t-test analysis. The level of significance was set at $5 \%(p<0.05)$.
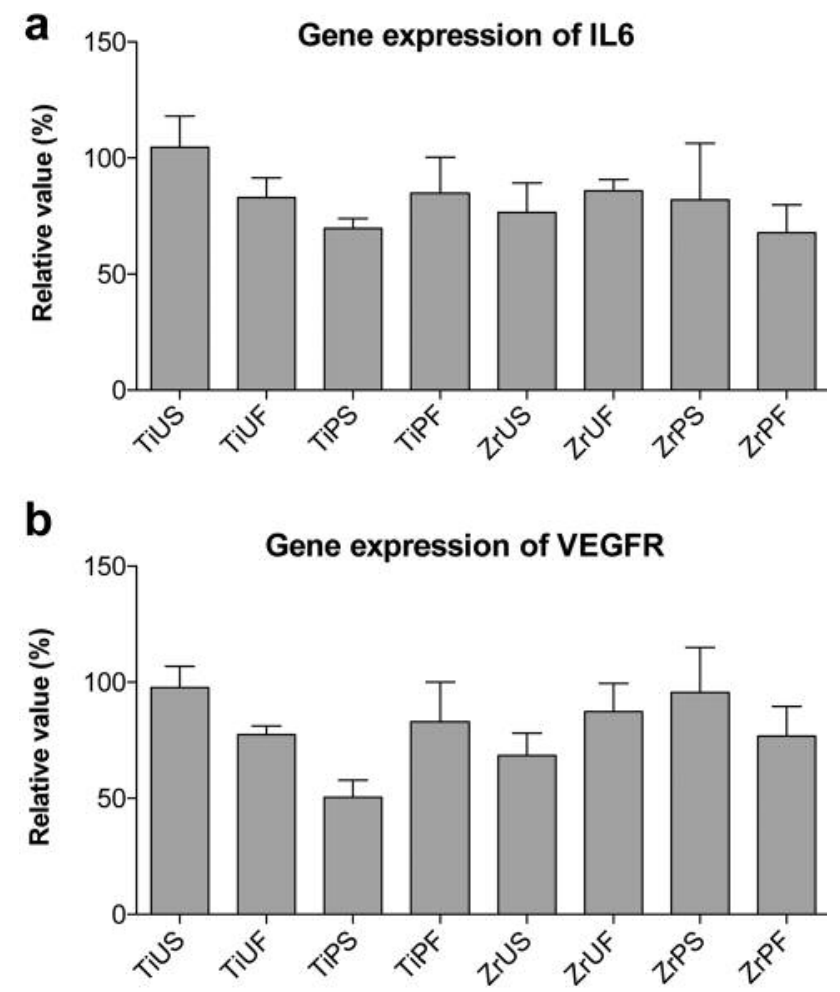

Figure 11. mRNA levels of IL-6 (A) and VEGF (B) of human gingival fibroblasts grown on surfaces of zirconia and titanium cleaned by steam or by a 3-step ultrasonic cleaning and disinfection protocol. Columns represent mean values of quadruplicate measurements. The mRNA level of each sample was normalized to that of control cells cultured on standard cell culture surface. 
in vivo $33: 689-698(2019)$

Table I. Surface roughness parameters obtained from 3D measurement of untreated ( $T i U, \mathrm{ZrU}$ ) and polished (TiP, ZrP) titanium and zirconia test samples. Avarage surface roughness (Sa $\mu \mathrm{m})$, maximum height of selected surface $(S z \mu \mathrm{m})$, and developed interfacial area ratio (Sdr \%).

\begin{tabular}{|c|c|c|c|c|c|c|c|c|c|c|}
\hline & \multicolumn{5}{|c|}{ CAD/CAM Titanium Untreated } & \multicolumn{5}{|c|}{ CAD/CAM Titanium Panther Polished } \\
\hline & $\begin{array}{l}\text { Sample } \\
\text { TiU \#01 }\end{array}$ & $\begin{array}{c}\text { Sample } \\
\text { TiU \#02 }\end{array}$ & $\begin{array}{c}\text { Sample } \\
\text { TiU \#03 }\end{array}$ & $\begin{array}{c}\text { Sample } \\
\text { TiU \#04 }\end{array}$ & $\begin{array}{l}\text { Mean } \\
\text { Value }\end{array}$ & $\begin{array}{l}\text { Sample } \\
\text { TiP \#01 }\end{array}$ & $\begin{array}{l}\text { Sample } \\
\text { TiP \#02 }\end{array}$ & $\begin{array}{l}\text { Sample } \\
\text { TiP \#03 }\end{array}$ & $\begin{array}{l}\text { Sample } \\
\text { TiP \#04 }\end{array}$ & $\begin{array}{l}\text { Mean } \\
\text { Value }\end{array}$ \\
\hline $\mathrm{Sa} \mu \mathrm{m}$ & 0.701 & 0.696 & 0.663 & 0.702 & 0.691 & 0.281 & 0.322 & 0.303 & 0.300 & 0.302 \\
\hline $\mathrm{Sz} \mu \mathrm{m}$ & 9.162 & 12.266 & 5.372 & 6.595 & 8.349 & 4.642 & 5.847 & 4.683 & 6.958 & 5.533 \\
\hline \multirow[t]{3}{*}{$\mathrm{Sdr} \%$} & 2.059 & 1.645 & 1.154 & 1.279 & 1.534 & 0.467 & 0.606 & 0.518 & 0.484 & 0.518 \\
\hline & \multicolumn{5}{|c|}{ CAD/CAM Zirconia Untreated } & \multicolumn{5}{|c|}{ CAD/CAM Zirconia Panther Polished } \\
\hline & $\begin{array}{c}\text { Sample } \\
\text { ZrU \#01 }\end{array}$ & $\begin{array}{c}\text { Sample } \\
\text { ZrU \#02 }\end{array}$ & $\begin{array}{c}\text { Sample } \\
\text { ZrU \#03 }\end{array}$ & $\begin{array}{c}\text { Sample } \\
\text { ZrU \#04 }\end{array}$ & $\begin{array}{l}\text { Mean } \\
\text { Value }\end{array}$ & $\begin{array}{l}\text { Sample } \\
\text { ZrP \#01 }\end{array}$ & $\begin{array}{l}\text { Sample } \\
\text { ZrP \#02 }\end{array}$ & $\begin{array}{l}\text { Sample } \\
\text { ZrP \#03 }\end{array}$ & $\begin{array}{l}\text { Sample } \\
\text { ZrP \#04 }\end{array}$ & $\begin{array}{l}\text { Mean } \\
\text { Value }\end{array}$ \\
\hline $\mathrm{Sa} \mu \mathrm{m}$ & 0.682 & 0.002 & 0.001 & 0.002 & 0.172 & 0.388 & 0.316 & 0.396 & 0.363 & 0.366 \\
\hline $\mathrm{Sz} \mu \mathrm{m}$ & 11.085 & 9.669 & 10.499 & 10.495 & 10.437 & 8.855 & 4.543 & 7.141 & 4.921 & 6.365 \\
\hline Sdr $\%$ & 0.904 & 1.774 & 1.622 & 2.241 & 1.635 & 0.907 & 0.591 & 0.985 & 0.746 & 0.807 \\
\hline
\end{tabular}

IL-6 and VEGFA match almost perfectly with each other. In other words, in each pair of steam/ ultrasonically cleaned surfaces, the samples with high IL-6 expression also showed higher VEGFA expression. However, differences between the applied cleaning methods showed no uniform trend. While for TiU and ZrP, Finevo sonic cleaning resulted in lower IL-6 and VEGFA expression than steam cleaning, it was the other way around for TiP and $\mathrm{ZrU}$.

\section{Discussion}

In the current study, steam cleaning and an antibacterial sonication cleaning process were compared regarding their effect on cells in vitro. Generally, good cell viability was observed for all tested abutment surfaces, indicating satisfactory cell attachment. The 3-step ultrasonic disinfection and cleaning protocol exhibited superior cytocompatibility on panther polished zironia specimens, compared to conventionally steam-cleaned samples. However, only one type of cells was used in this study. It is well possible that gingival fibroblasts are not sensitive to contaminants on the surfaces of these specimens. In a previous study (11), the surfaces of zirconia and titanium samples were ultrasonically cleaned with a special washing reagent containing proteinase, detergent and EDTA, and/ or a vacuum plasma protocol. While the washing reagent led to an increased cell number on the suface, the plasma treatment did not seem to have any effect. A possible explanation is that protease and detergent are important while physical cleaning methods, such as plasma treatments, may be less effective. By contrast, another recent study showed enhanced numbers and cell spreading areas of adherent osteoblasts on plasma treated surfaces in vitro (28). Nakajima et al. also reported significantly reduced mRNA levels of IL-6 and VEGFA by either surface-treatment (11). By way of comparison, we did not find such effects with ultrasonically cleaned surfaces. However, immflamation is a complex biological process and may not be adequately assessed in simple in vitro systems.

In summary, cell attachment to the tested surfaces was generally good. For zirconia CAD/CAM disks polished by Panther Edition Lense 260 rough and 260 smooth instruments (ZrPU), sonication provided better results over the control steam cleaning procedure. For all other three material/ surface treatment combinations, no such difference was observed. The cleaning procedures utilized did not have any negative effect either. Therefore the null hypothesis could not be confirmed by the results of this study. The tested 3-step ultrasonic protocol did not universally demonstrate enhanced HGF-cell attachment and a reduced inflammatory cytokine response on CAD/CAM abutment surfaces. Further in vitro and in vivo studies are neccessary to clarify this issue. More importantly, clinical outcomes of implant abutments and superstructures cleaned by various methods will provide valuable evidence as to whether a specific cleaning procedure is substantially advantageous in reducing the risk of peri-implant inflammation.

\section{Conflicts of Interest}

BEGO Implant Systems GmbH \& Co. KG provided the CAD/CAM disks for the experimental investigation. The design, documentation and analyses of this study were completed entirely independent of BEGO Implant Systems. The Authors declare that they have no conflict of interest. 


\section{Authors' Contributions}

PG, RS2, PH and CF contributed to the design of the study. FT contributed to the topography and surface analysis. DD contributed to microscopic and chemical analysis. PH contributed to the cell culture, viability and gene expression assays. PG, RS2, MG, REF, EM, PH and RS7 contributed to study selection and data extraction. All authors read, revised, and approved the final manuscript.

\section{Acknowledgements}

The Authors gratefully acknowledge Lan Kluwe for her contribution in preparing the manuscript and Jane Rehberg for excellent technical assistance. The Authors thank BEGO Implant Systems GmbH \& Co. $\mathrm{KG}$ for providing the $\mathrm{CAD} / \mathrm{CAM}$ disks for the experimental investigation.

\section{References}

1 Esposito M, Hirsch JM, Lekholm U and Thomsen P: Biological factors contributing to failures of osseointegrated oral implants. (ii). Etiopathogenesis. Eur J Oral Sci 106(3): 721-764, 1998. PMID: 9672097.

2 Tallarico M, Canullo L, Caneva M and Ozcan M: Microbial colonization at the implant-abutment interface and its possible influence on periimplantitis: A systematic review and metaanalysis. J Prosthodont Res 61(3): 233-241, 2017. PMID: 28359872. DOI: 10.1016/j.jpor.2017.03.001

3 Atsuta I, Ayukawa Y, Kondo R, Oshiro W, Matsuura Y, Furuhashi A, Tsukiyama Y and Koyano K: Soft tissue sealing around dental implants based on histological interpretation. J Prosthodont Res 60(1): 3-11, 2016. PMID: 26725967. DOI: 10.1016/j.jpor.2015.07.001

4 Moon IS, Berglundh T, Abrahamsson I, Linder E and Lindhe J: The barrier between the keratinized mucosa and the dental implant. An experimental study in the dog. J Clin Periodontol 26(10): 658-663, 1999. PMID: 10522777.

5 Pabst AM, Walter C, Grassmann L, Weyhrauch M, Brullmann DD, Ziebart T, Scheller $\mathrm{H}$ and Lehmann KM: Influence of $\mathrm{cad} / \mathrm{cam}$ all-ceramic materials on cell viability, migration ability and adenylate kinase release of human gingival fibroblasts and oral keratinocytes. Clin Oral Investig 18(4): 1111-1118, 2014. PMID: 23996379. DOI: 10.1007/s00784-013-1098-9

6 Piattelli A, Pontes AE, Degidi M and Iezzi G: Histologic studies on osseointegration: Soft tissues response to implant surfaces and components. A review. Dent Mater 27(1): 53-60, 2011. PMID: 21122902. DOI: 10.1016/j.dental.2010.10.019

7 Rupp F, Gittens RA, Scheideler L, Marmur A, Boyan BD, Schwartz Z and Geis-Gerstorfer J: A review on the wettability of dental implant surfaces i: Theoretical and experimental aspects. Acta Biomater 10(7): 2894-2906, 2014. PMID: 24590162. DOI: $10.1016 /$ j.actbio.2014.02.040

8 Rupp F, Liang L, Geis-Gerstorfer J, Scheideler L and Huttig F: Surface characteristics of dental implants: A review. Dent Mater 34(1): 40-57, 2018. PMID: 29029850.

9 Canullo L, Micarelli C, Lembo-Fazio L, Iannello $G$ and Clementini M: Microscopical and microbiologic characterization of customized titanium abutments after different cleaning procedures. Clin Oral Implants Res 25(3): 328-336, 2014. PMID: 23210704. DOI: 10.1111/clr.12089
10 Canullo L, Penarrocha-Oltra D, Marchionni S, Bagan L, Penarrocha-Diago MA and Micarelli C: Soft tissue cell adhesion to titanium abutments after different cleaning procedures: Preliminary results of a randomized clinical trial. Med Oral Patol Oral Cir Bucal 19(2): e177-183, 2014. PMID: 24121917.

11 Nakajima K, Odatsu T, Shinohara A, Baba K, Shibata Y and Sawase T: Effects of cleaning methods for custom abutment surfaces on gene expression of human gingival fibroblasts. J Oral Sci 59(4): 533-539, 2017. PMID: 29279567. DOI: 10.2334/ josnusd.16-0681

12 Canullo L, Micarelli C and Iannello G: Microscopical and chemical surface characterization of the gingival portion and connection of an internal hexagon abutment before and after different technical stages of preparation. Clin Oral Implants Res 24(6): 606-611, 2013. PMID: 22587335. DOI: 10.1111/j.1600-0501.2012.02499.x

13 Gehrke P and Tabellion A: Microscopical and chemical surface characterization of cad/cam zircona abutments after different cleaning procedures. A qualitative analysis. 7(2): 151-159, 2015. PMID: 25932314. PMCID: PMC4414946. DOI: 10.4047/ jap.2015.7.2.151

14 Mishra PK, Wu W, Rozo C, Hallab NJ, Benevenia J and Gause WC: Micrometer-sized titanium particles can induce potent th2type responses through tlr4-independent pathways. J Immunol 187(12): 6491-6498, 2011. PMID: 22095717. DOI: 10.4049/ jimmunol.1101392

15 Canullo L, Penarrocha D, Micarelli C, Massidda O and Bazzoli M: Hard tissue response to argon plasma cleaning/sterilisation of customised titanium abutments versus 5-second steam cleaning: Results of a 2-year post-loading follow-up from an explanatory randomised controlled trial in periodontally healthy patients. Eur J Oral Implantol 6(3): 251-260, 2013.PMID: 24179979.

16 Esposito M: The editor's point of view: On the study on argonplasma cleaning of customised abutments. Eur J Oral Implantol 8(3): 213, 2015. PMID: 26355166.

17 Kern M: On the scientific evidence that the sterilization of customized implant abutments is required. Eur J Oral Implantol 8(3): 219, 2015. PMID: 26355174.

18 Aronsson BO: On argon-plasma cleaning - some comments from regulatory and scientific perspectives. Eur J Oral Implantol 8(3): 211-212, 2015. PMID: 26355165.

19 Mehl C, Kern M, Zimmermann A, Harder S, Huth S and Selhuber-Unkel C: Impact of cleaning procedures on adhesion of living cells to three abutment materials. Int J Oral Maxillofac Implants 32(5): 976-984, 2017. PMID: 28906501. DOI: 10.11607/jomi.5630

20 Li KC, Waddell JN, Prior DJ, Ting S, Girvan L, van Vuuren LJ and Swain MV: Effect of autoclave induced low-temperature degradation on the adhesion energy between yttria-stabilized zirconia veneered with porcelain. Dent Mater 29(11): e263-270, 2013. PMID: 24007922. DOI: 10.1016/j.dental.2013.08.204

21 Hallmann L, Mehl A, Ulmer P, Reusser E, Stadler J, Zenobi R, Stawarczyk B, Ozcan M and Hammerle CH: The influence of grain size on low-temperature degradation of dental zirconia. J Biomed Mater Res B Appl Biomater 100(2): 447-456, 2012. PMID: 22121144. DOI: 10.1002/jbm.b.31969

22 Flinn BD, deGroot DA, Mancl LA and Raigrodski AJ: Accelerated aging characteristics of three yttria-stabilized tetragonal zirconia polycrystalline dental materials. J Prosthet Dent 108(4): 223-230, 2012. PMID: 23031728. DOI: 10.1016/ S0022-3913(12)60166-8 
23 Lee TH, Lee SH, Her SB, Chang WG and Lim BS: Effects of surface treatments on the susceptibilities of low temperature degradation by autoclaving in zirconia. J Biomed Mater Res B Appl Biomater 100(5): 1334-1343, 2012. PMID: 22566390. DOI: $10.1002 / \mathrm{jbm} . b .32700$

24 Kim JW, Covel NS, Guess PC, Rekow ED and Zhang Y: Concerns of hydrothermal degradation in cad/cam zirconia. J Dent Res 89(1): 91-95, 2010. PMID: 19966039. DOI: 10.1177/ 0022034509354193

25 Canullo L, Tallarico M, Penarrocha M, Corrente G, Fiorellini J and Penarrocha D: Plasma of argon cleaning treatment on implant abutments in periodontally healthy patients: Six years postloading results of a randomized controlled trial. Int J Periodontics Restorative Dent 37(5): 683-690, 2017. PMID: 28817132. DOI: $10.11607 /$ prd.3079

26 Farronato D, Fumagalli D, Asa'ad F and Rasperini G: Decontamination of customized laser-microtextured titanium abutments: A comparative in vitro study of different cleaning procedures. Int J Periodontics Restorative Dent 38(5): e87-e95, 2018. PMID: 29677228. DOI: $10.11607 / \operatorname{prd} .3250$
27 Akira S, Taga T and Kishimoto T: Interleukin-6 in biology and medicine. Adv Immunol 54: 1-78, 1993. PMID: 8379461.

28 Canullo L, Genova T, Wang HL, Carossa S and Mussano F: Plasma of argon increases cell attachment and bacterial decontamination on different implant surfaces. Int $\mathrm{J}$ Oral Maxillofac Implants 32(6): 1315-1323, 2017. PMID: 29140375. DOI: $10.11607 /$ jomi.5777
Received February 14, 2019

Revised March 10, 2019

Accepted March 12, 2019 